\title{
Complete agenesis of the right hemi-diaphragm in an adult: Case report and literature review
}

DOI: https://doi.org/10.32007/jfacmedbagdad.6331850.

\author{
Abdulsalam Y. Taha* \\ Kalandar H.A. Kaznazani** \\ FICMS \\ DM, FRCS (Glasg), FACS, FICS.
}

This work is licensed under a Creative Commons Attribution-NonCommercial 4.0 International License

\begin{abstract}
:
Congenital agenesis of the hemi-diaphragm (AHD) in adults is rare and exceedingly so on the right side. Since its first recognition in 1959, no more than nine cases have been published in the English literature by the year 2016. "Partial diaphragm agenesis" is actually a large congenital

JFac Med Baghdad 2021; Vol.63, No. 3 Received: May, 2021 Accepted: Aug., 2021 Published: Oct., 2021 diaphragmatic hernia $(\mathrm{CDH})$ rather than true AHD. Respiratory compromise is the likely presentation. However, patients may survive for years without symptoms. Despite a straightforward clinical and radiographic diagnosis of AHD, the best method of repair is controversial. Herein, we present a case of complete right-sided AHD in a 54 year old man diagnosed upon surgical exploration 16 years earlier. Despite trans-thoracic mesh repair, the patient experienced only a modest improvement of his shortness of breath (SOB). Although the liver persisted high in the chest as shown by serial CT scans of the chest, polypropylene mesh was effective in preventing further visceral herniation. Adult patients with right-sided AHD always deserve operative intervention to avoid the potential complications.

Keywords: Congenital, agenesis, unilateral, diaphragm, adult.
\end{abstract}

\section{Introduction:}

Embryonic formation of the diaphragm takes place during the $3^{\text {rd }}-8^{\text {th }}$ weeks of intrauterine life through the participation of four major structures namely septum transversum, pleuro-peritoneal membrane, dorsal mesentery of the esophagus and the innermost thoracic wall [1]. Agenesis of the hemi-diaphragm (AHD) refers to the complete absence of the hemidiaphragm on one or both sides. Such congenital anomaly is thought to result from the failure of the pleuro-peritoneal membrane to close the pleuroperitoneal canal or the failure of the development of all four precursor components of the developing diaphragm [2-4]. Bilateral AHD is very rare [5] and infants with this defect rarely survive to have surgical intervention [6]. Unilateral AHD is mostly left-sided while the right-sided cases are extremely rare [7]. Most patients with congenital AHD present very early in life [3] and only few patients have been reported to reach adulthood [8]. Since Bingham first recognized AHD as a distinct entity in 1959 and until 2016, nine adults with this anomaly have been described [9]. The oldest reported adult patient presenting with true agenesis of the hemi-diaphragm in the English literature was a 66-year old lady [3].

*Corresponding Author: Dept. of Thoracic and Cardiovascular Surgery, College of Medicine, University of Sulaimani. abdulsalam.taha@univsul.edu.iq

**Director of Kurdistan Board for Digestive Surgery/ Sulaimani center.Email: drqalandaar@gmail.com.
Herein, we present a case of complete right-sided AHD in a 54 year old man diagnosed upon surgical exploration 16 years earlier. Despite mesh repair, the patient experienced only a modest improvement of his shortness of breath (SOB). The case is discussed in this report with a review of the relevant literature.

\section{Case Report}

A 54-year old male military officer was seen several times after an old right thoracotomy because of chronic shortness of breath (SOB), wheezy chest and post-thoracotomy neuralgia. The physical exam revealed a scar of posterolateral thoracotomy, diffuse rhonchi and decreased intensity of breath sounds on auscultating the right chest. The patient was a known asthmatic for many years and was operated upon 16 years earlier for suspected huge congenital rightsided diaphragmatic hernia. He never smoked but was one of the victims of a chemical weapon attack on his village in 1988. The presenting preoperative symptom was progressive SOB of several years' duration. Examination of the chest prior to surgery revealed a diminished intensity of breath sounds over the right chest. Plain chest radiograph (PA and lateral views) (Fig $1 \mathrm{~A}-\mathrm{B})$ showed a great apparent elevation of right hemi-diaphragm. CT scan of the chest (Fig 2 $\mathrm{A}$ and $\mathrm{B}$ ) showed the herniation of the entire liver into the right thoracic cavity. Likewise, right thoracotomy confirmed the presence of the whole liver in the right pleural space. To our surprise, the right hemidiaphragm was completely missing which favored the 
diagnosis of diaphragmatic agenesis rather than diaphragmatic hernia per se. The liver was pushed down and a big Polypropylene mesh $(30 \mathrm{~cm}$ x $30 \mathrm{~cm})$ was used to replace the diaphragm by suturing it into the ribs (Fig 3). The patient experienced only a modest clinical improvement following surgery.
However, the follow up chest radiograph (Fig 4 A) and chest CT scan (Fig 4 B) revealed persistently high liver position. Despite his illness, the patient is still serving in the army while his chest pain and dyspnea are being conservatively managed.
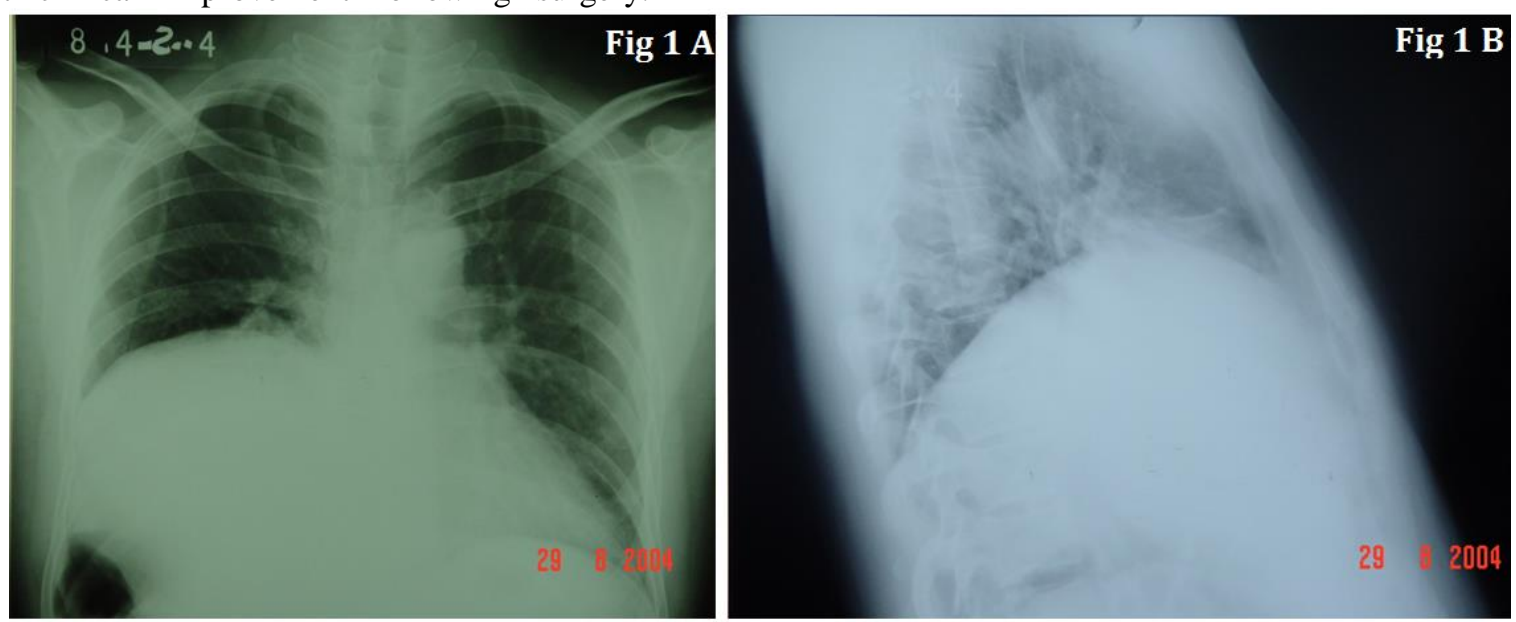

Fig 1: Preoperative (PA) chest radiograph (A) and lateral view (B) showing great apparent elevation of the right hemi-diaphragm suggestive of a huge right-sided diaphragmatic hernia.
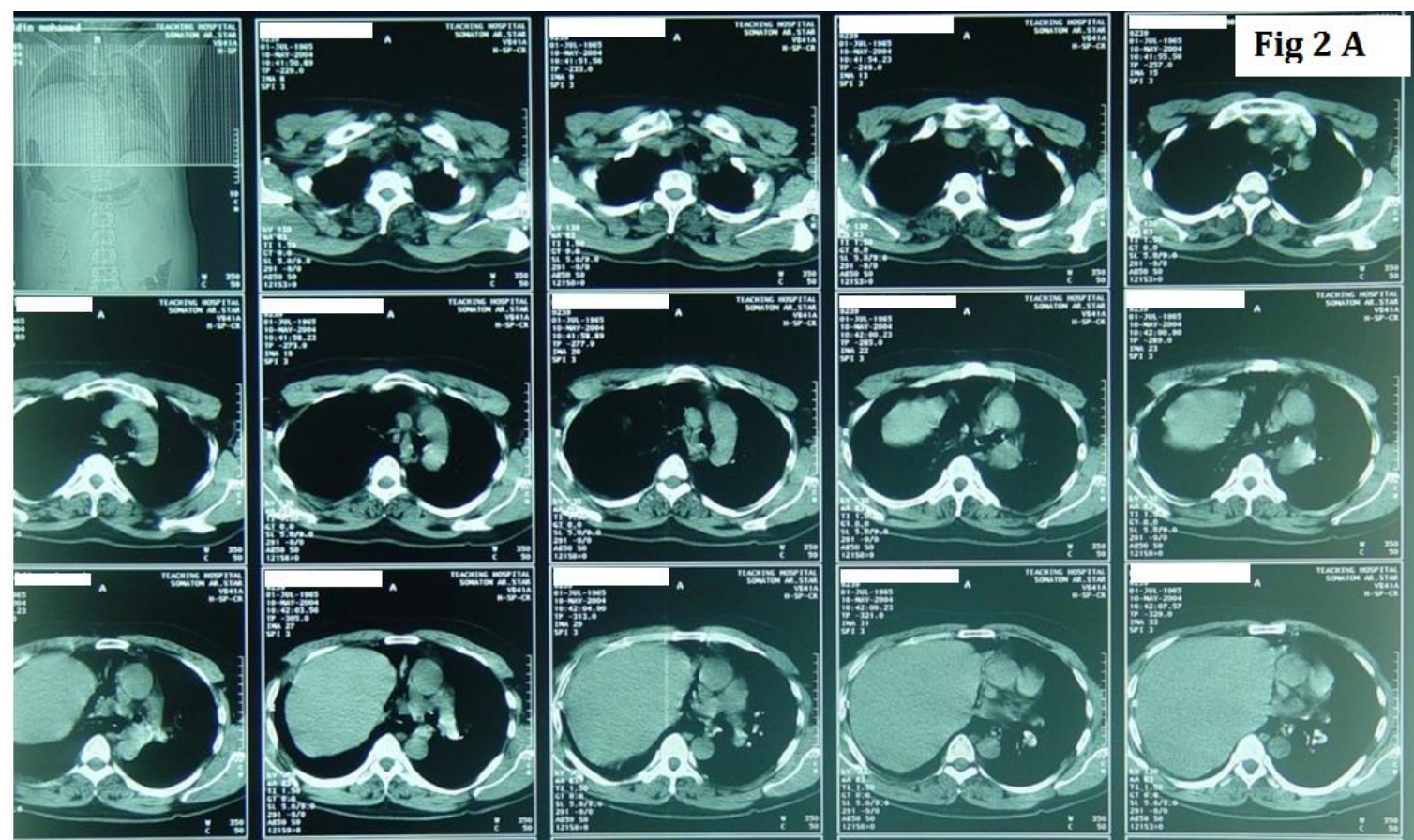

Fig 2 A: CT scan of the chest prior to surgery. 


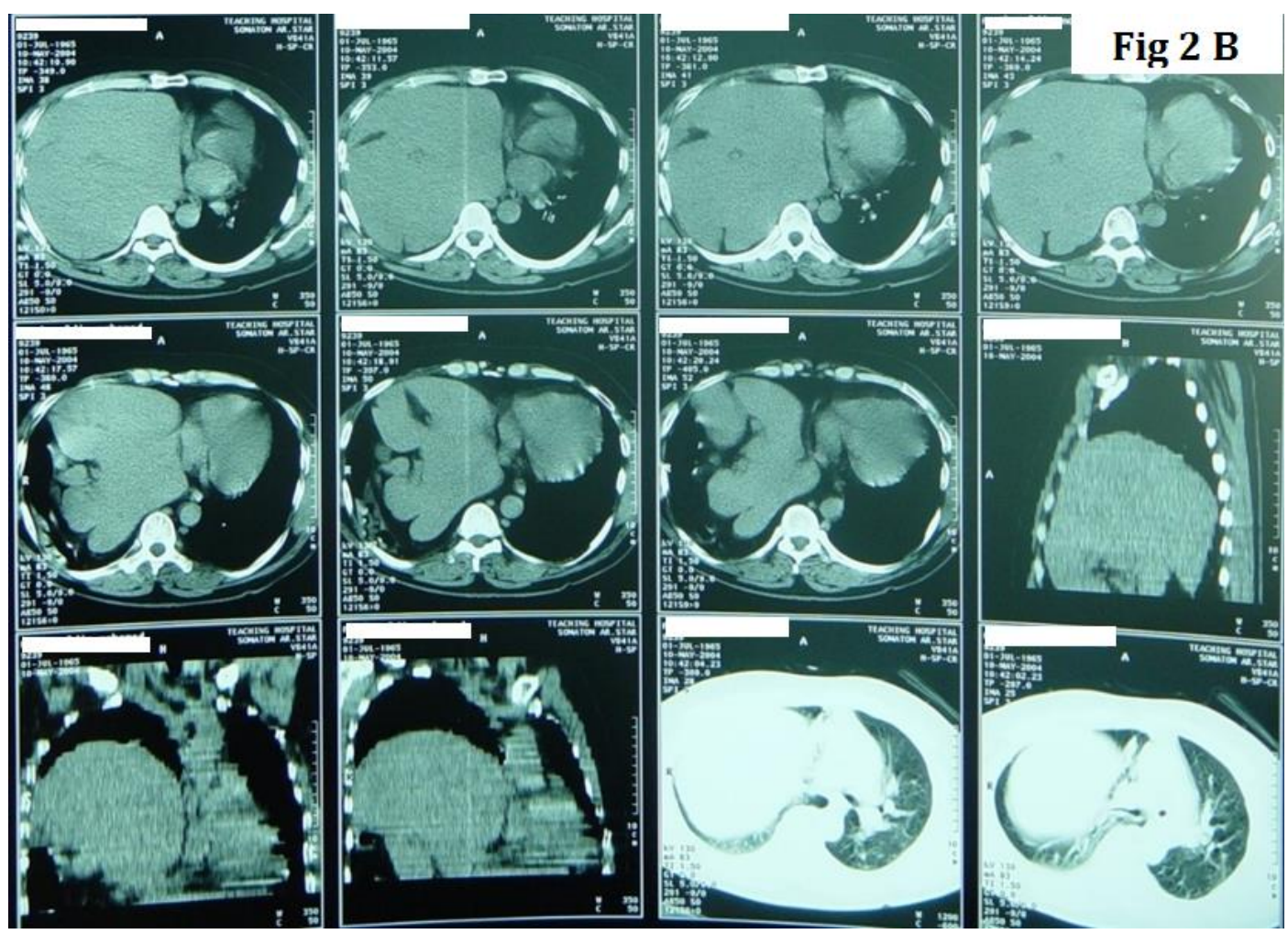

Fig 2 B: CT scan of the chest prior to surgery showing evidence of huge right-sided diaphragmatic hernia.

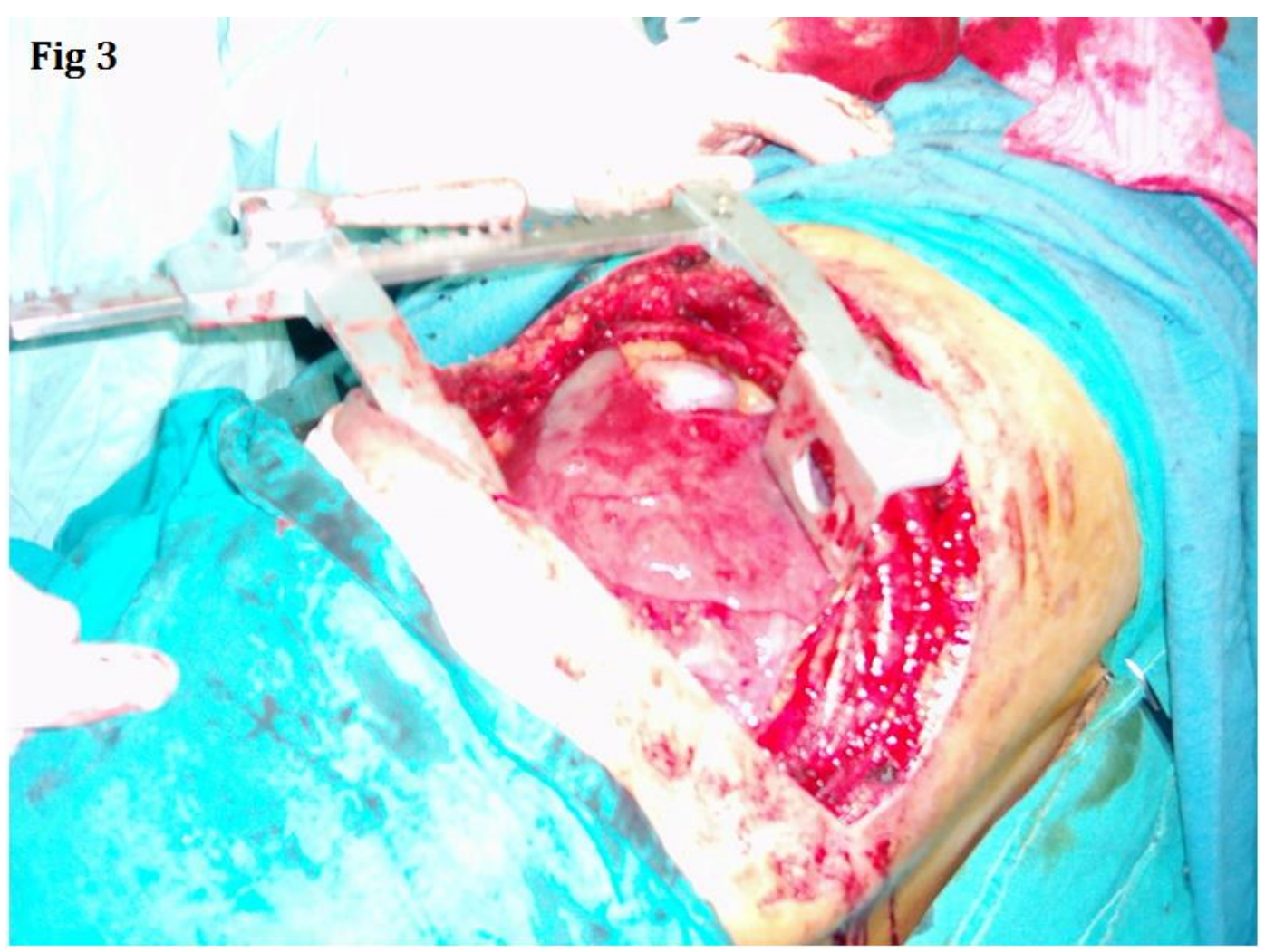

Fig 3: Operative photograph showing liver herniation into the right side of the chest with complete absence of the right diaphragm. 

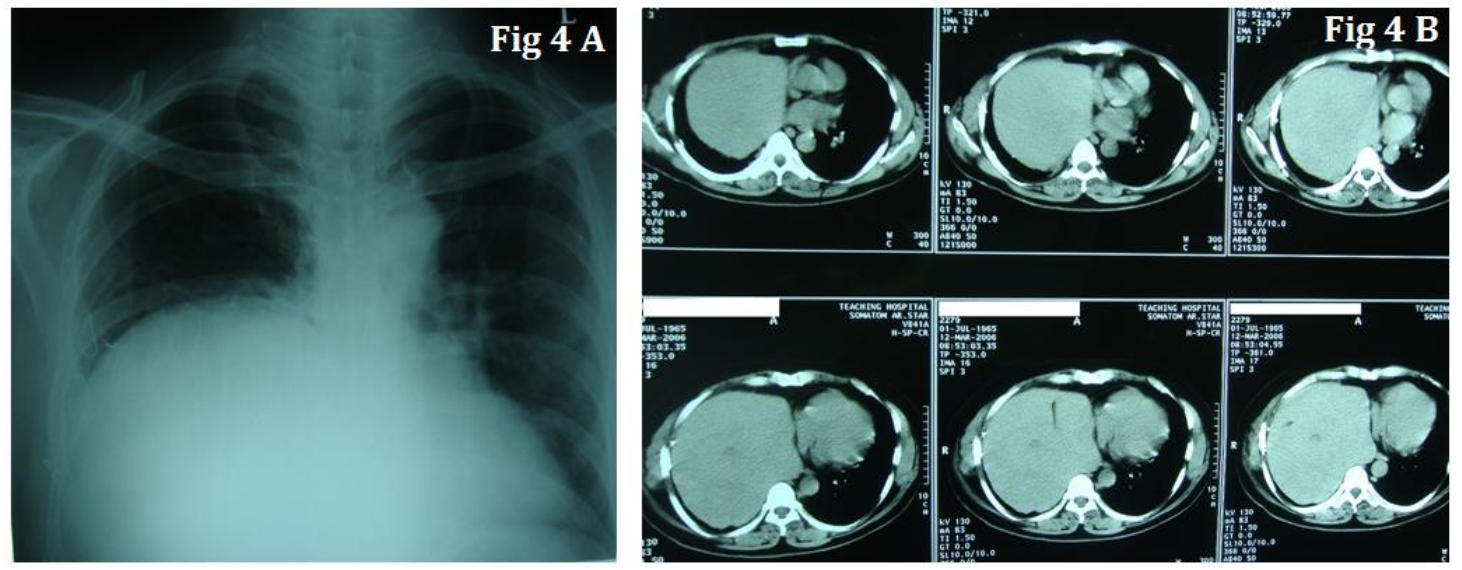

Fig 4: Follow up chest radiograph (A) and CT scan of the chest (B) 4 years after surgery showing persistent liver opacity high in the chest.

\section{Discussion:}

The diaphragm is the most important muscle in the body after the heart. Moreover, it is the most important respiratory muscle [1]. Ordinarily, the diaphragm separates the thorax from the abdomen and prevents the herniation of abdominal viscera into the chest. For reasons not completely understood, the diaphragm may be subjected to congenital malformations such as congenital diaphragmatic hernias $(\mathrm{CDH})$ and rarely congenital unilateral or bilateral agenesis [5][6]. The latter is a major anomaly that occurs alone or in combination with congenital defects in one or more body organs such as the lungs, limbs, heart, gastro-intestinal tract and central nervous system [9]. Literally-speaking, agenesis of the diaphragm refers to the absence of this vital musculo-aponeurotic structure. The consequences of diaphragmatic agenesis include: Stillbirths [5], early neonatal deaths [6] and rarely survival to adulthood [3][7-10]. The rare bilateral agenesis is so severe that neonates seldom survive to get surgical repair [6] while few patients with unilateral variants have survived to adulthood and have been reported so far [3][7-10]. Diaphragmatic agenesis represents the rarest and most extreme type of congenital diaphragmatic hernias [10]. Some authors referred to huge diaphragmatic hernias with little diaphragmatic muscle at the time of surgical exploration as partial agenesis of the diaphragm [2]. We disagree with this notion and believe that whenever the rim of the diaphragm is visible at surgical exploration, the case should be considered diaphragmatic hernia rather than agenesis. Travaline and Cordova [3] reported three cases of presumed AHD. However, Sheehan et al believe that these cases were actually large $\mathrm{CDHs}$ as mesh repair was performed using remnant of the diaphragm in two of them [3].The incidence of congenital diaphragmatic agenesis (CDA) is one in 250,000 births. In contrast, the frequency of $\mathrm{CDH}$ is one in 2,200-2,450 births [4]. The incidence of CDA is reportedly $27-31 \%$ of cases of CDH. The incidence of adults with CDA is likely to increase in the future due to the higher survival rates of neonates who receive better care [9]. In our case, the hemi-diaphragmatic agenesis was on the right side showing rare side of occurrence of a very rare lesion. Diaphragmatic agenesis occurs on the left side in $88-97 \%$ of the cases, while right-sided defects are less common due to the earlier closure of the right pleuro-peritoneal canal. Moreover, even if right-sided diaphragmatic defects are present, the liver prevents herniation through such defects [7]. Diagnostic workup made in early infancy generally reveals associated genetic malformations, particularly aneuploidy syndromes [7][8][10]. Diagnosis of CDA in adults is based on a high index of clinical suspicion supported by imaging studies. In adults with CDA presenting with cardiopulmonary or digestive symptoms, the main task should be systematic examination of the gastrointestinal tract to rule out pathological lesions in the herniated intrathoracic viscera [9]. The index case was a 38year-old military officer reasonably active despite his progressive SOB. He was initially suspected to have a huge congenital DH according to his symptoms as well as the radiological findings. However, complete absence of diaphragmatic muscle at surgical exploration favored the diagnosis of diaphragmatic agenesis. Since we had no alternative, we elected to repair the lesion by a mesh despite the previously reported high complication rate associated with this type of repair [2]. The drawbacks of a synthetic mesh repair include recurrence of the defect, patch dislodgement or infection, progressive chest wall deformities and restrictive pulmonary function [4]. On the other hand, some consider an elective repair of AHD by a prosthetic mesh an optimum option [3]. Adult patients with right-sided agenesis are in need of surgical intervention to prevent the herniation of the liver and other abdominal organs. Surgery is also indicated in symptomatic patients with dyspnea or organ herniation to prevent worsening of lung function or visceral damage [3]. The surgical repair 
of the lesion is very difficult due to the complete absence of the diaphragmatic tissue needed to achieve the repair. Several authors used different therapeutic choices such as prosthesis, abdominal wall and chest wall muscle flaps, suturing the chest margins with the liver, use of pre-renal fascia while some recommended no repair at all [2]. The review of the literature revealed sporadic case reports of left and very occasionally right diaphragmatic agenesis in adult patients who were symptomatic or free from symptoms and underwent surgical repair by different techniques or otherwise were managed conservatively [2]. Al-Zayer et al. presented a case of a 27-year-old lady, who was referred two days after a Caesarean section with suspected pulmonary embolism. CT scan of the chest showed herniation of the liver and intestine into the right hemi-thorax. Exploratory right thoracotomy revealed right diaphragmatic agenesis. The herniated viscera were reduced into the abdomen, and the defect was closed using a mesh. The patient had a smooth postoperative recovery and left the hospital 10 days later [7]. Ali et al. described the case of a women who presented with progressive SOB during the last trimester of her gestation with total agenesis of the right hemidiaphragm. Polypropylene mesh was used to fashion a new diaphragm which was followed by good lung expansion and improvement of the patient's symptoms [10]. Sheehan et al. described a 66-yearold lady who presented with obstruction of the large bowel and discovered to have a complete absence of the left hemi-diaphragm and intra-thoracic transverse colon and splenic flexure during exploratory laparotomy. A transverse colectomy with end-to-end anastomosis was done. Mesh repair was considered unsuitable because of the risk of infection. The patient left the hospital on day 60 and was found well one year after surgery although her left hemi-diaphragm was not substituted [3]. Sesitashvili et al. described a 63 year old man who presented with small bowel intussusception because of strangulated intestinal obstruction and peritonitis. During exploratory laparotomy, partial right-sided agenesis of the diaphragm was found. Owing to the poor overall status of the patient, repair of the diaphragm with a synthetic mesh was deferred for the future [8]. It is of interest to note that in one article [9], the authors described successful laparoscopic cholecystectomy in a 36-year old lady with a previously undiagnosed complete right-sided diaphragmatic agenesis. Samuel and Parapurath reported the first successful primary repair of a complete CDA in a neonate using flaps of latissimus dorsi and serratus anterior muscles reinforced by a flexible composite mesh. The authors believe that their technique provides the patients with an intact compliant functional muscular structure [4]. We wonder if the results of this repair technique of CDA in neonates are similarly applicable to adult patients. In our case, mesh repair was done but the improvement in respiratory performance was just modest. This could be partly attributed to bronchial asthma and previous exposure to chemical weapons. On the other hand, the high position of the mesh could be another contributing factor. Though mesh repair didn't achieve optimum result, we think it was effective in preventing further herniation of abdominal viscera into the right chest and potential complications.

\section{Conclusion:}

Complete agenesis of hemi-diaphragm in adults is very rare and exceedingly so on the right side. Though clinical and radiographic diagnosis may be straightforward, differentiation from the more common large congenital diaphragmatic hernia may be made only at the time of surgery. To avoid potential complications of right-sided lesions, operative treatment is advised yet the best method of repair is controversial.

\section{Consent:}

The patient gave his informed consent to publish his case and the accompanying images.

\section{Authors' Contribution:}

Abdulsalam Y Taha has contributed to study conception, study design, acquisition of data analysis, interpretation of data, drafting of manuscript and critical revision. Kalandar Kaznazani has contributed to the clinical management of the case.

\section{References}

[1] Anraku M, Shargall Y. Surgical Conditions of the Diaphragm: Anatomy and Physiology. Thorac Surg Clin

doi:10.1016/j.thorsurg.2009.08.002

[2] Mirza B, Bashir Z, Sheikh A. Congenital right hemidiaphragmatic agenesis. Lung India 2012;29(1):53-55

[3] Sheehan JJ, Kearns SR, McNamara DA, Brennan RP, Deasy JM. Adult Presentation of Agenesis of the Hemi-diaphragm. Chest 2000;117(3):901-902. https://doi.org/10.1378/chest.117.3.901

[4] Samuel M, Parapurath R. Primary combined Latissimus Dorsi and Serratus Anterior Flap Repair of Right-Sided Congenital Diaphragmatic Agenesis in a Neonate. Sultan Qaboos University Med J 2016;16(1):e96-e100

[5] Loo CK, Pereira TN, Ramm GA. Case Report: Fetal Bilateral Diaphragmatic Agenesis, Ectopic Liver and Abnormal Pancreas. Fetal Pediatr Pathol 2015;34(4):216-22.

[6] Wang SM, Lin CH, Lin YJ, Yang HB, Wu MH. Congenital bilateral agenesis of diaphragm: report of a case. Eur J Pediatr 1997;156(7):572-4

[7] Al-Zayer F, Aljaroof AH, Al-Marhoun $M$, Abualsaud B, Al-Zaher M, Meshikhes A. Congenital right diaphragmatic hernia in an adult. Journal of Surgical Case Reports 2019; 12, 1-3

[8] Sesitashvili T, Tomadze G, Rekhviashvili A. A rare case of right diaphragm agenesis. Georgian Med News 2016;252:7-10

[9] Sagiroglu J, Tombalak E, Yilmaz SB, Balyemez $F$, Eren $T$, Alimoglu $O$. Laparoscopic cholecystectomy in an adult with agenesis of right hemidiaphragm and limb reduction defects: First 


\title{
عدم التخلق الكلي للحجاب الحاجز الأيمن عند البالغين: عرض حالة ومراجعة للأدبيات
}

\author{
د. عبدالسلام ياسين طه فرع جراحة الصدر والقلب والاوعية الدموية/ كلية الطب / جامعة سليمانية /كردستان العراق. \\ د. قلتندر كسنزاني فرع الجراحة عامه/ مستشفى السليمانية التعليمي/ كردستان العراق. \\ الخلاصة
}

يعد عدم التخلق الو لادي للحجاب الحاجز عند البالغين أمر ا نادر ا وأكثر ندرة في الجانب الايمن. ومنذ تشخيصه للمرة الأولى في في عام 1959

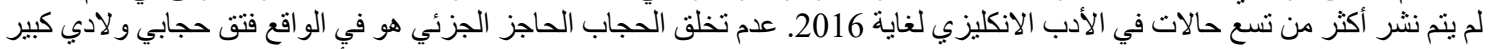

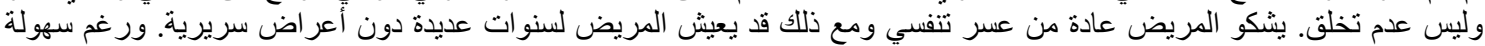

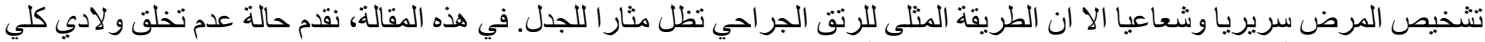

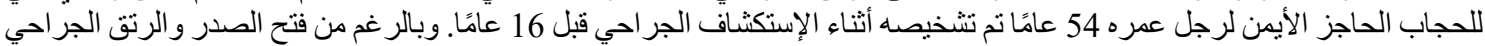

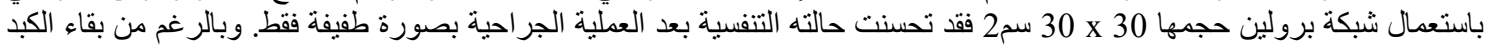

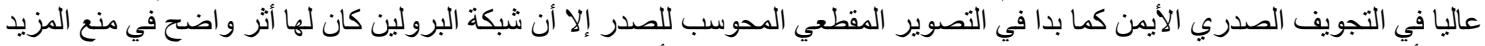

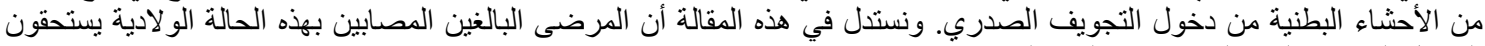

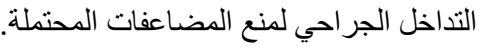
الكلمات المفتاحية عدم التخلق الو لادي، أحادي الجانب، الحجاب الحاجز، البالغون. 